\title{
A PROBLEMÁTICA AMBIENTAL E O VERDE URBANO
}

\author{
Mariana Cristina da Cunha Souza
}

\section{Margarete Cristiane de Costa Trindade Amorim}

RESUMO: É no contexto do intenso processo de industrialização e urbanização mundial, em meados da década de 1970, que a questão ambiental começa a ser disseminada pelo planeta, influenciando na organização e realização de eventos que buscam conhecer a gênese dos problemas que afetam o meio ambiente. O Brasil assumiu papel de destaque nessa discussão, porquanto cediou em 1992 na cidade do Rio de Janeiro, a Conferência Sobre o Meio Ambiente e o Desenvolvimento organizada pela Organização das Nações Unidas (ONU). Logo, são desenvolvidas no meio acadêmico análises sobre a qualidade ambiental e qualidade de vida no espaço urbano e, a partir disso, considerações importantes começam a ser visualizadas e compartilhadas através das pesquisas científicas, destacando-se neste artigo os benefícios da existência de vegetação para o espaço urbano, principalmente, os relacionados aos aspectos sociais, ambientais e estéticos da cidade. Entretanto, a realidade observada é de que há carência de áreas verdes no ambiente urbano brasileiro e falta de planejamento urbano desde a instituição até o manejo das áreas já efetivadas. Dessa forma, este artigo traz uma abordagem sobre a conceitualização das áreas verdes, evidenciando suas principais características e os benefícios por elas proporcionados, já que está cientificamente comprovado que a vegetação urbana, quando localizada no ambiente urbano e distribuída equitativamente, influencia generosamente para que haja qualidade ambiental e qualidade de vida da população.

Palavras Chave: Ambiente Urbano. Qualidade Ambiental. Vegetação.

\section{INTRODUÇÃO}


As inquietações relacionadas aos problemas ambientais têm tido o devido destaque, principalmente, a partir da década de 1970. Considerada por alguns estudiosos como a década do Meio Ambiente, foi marcada por acontecimentos de gênese conservacionista e de preservação ambiental (GREGORY, 1985).

A nível mundial, destaca-se a Conferência das Nações Unidas sobre Meio Ambiente Humano e Desenvolvimento realizada em Estocolmo na Suécia, no ano de 1972, onde buscou-se possíveis soluções técnicas para acabar com as desigualdades sociais e econômicas entre os países considerados do Primeiro e do Terceiro Mundo; realizar discussões sobre a crise dos combustíveis fósseis; sobre a redução nos índices de poluição e acerca da escassez dos recursos naturais (VIOLA, 1991; RODRIGUES, 1994).

O relatório conhecido como Nosso Futuro Comum, elaborado pela primeira-ministra da Noruega Sra. Gro Brundtland e por especialistas ambientais, realizou uma análise sobre as principais temáticas relacionadas ao desenvolvimento e ao meio ambiente. $\mathrm{O}$ documento publicado em 1987 tornou-se referência para as discussões da Conferência Sobre o Meio Ambiente e o Desenvolvimento, no Rio de Janeiro em 1992. A Conferência das Nações Unidas sobre Meio Ambiente reuniu representantes de 170 países e verificou os avanços adquiridos no campo ambiental desde a realização da Conferência de Estocolmo e também foram propostas estratégias para que as nações alcançassem 0 desenvolvimento com base na sustentabilidade (RODRIGUES, 1994; CASCINO, 2007).

Os eventos e o relatório citados, salvo suas diferenças, demonstraram a crescente discussão a nível global sobre a questão ambiental, tanto que em 2012, do dia 13 ao 22 de junho, realizou-se no Rio de Janeiro a Conferência das Nações Unidas sobre Desenvolvimento Sustentável, a $\mathrm{RIO}+20$, cujo objetivo foi renovar e reafirmar o compromisso político com o desenvolvimento sustentável. Dessa forma, a Conferência estava focada em torno de dois temas principais: a economia verde no contexto do desenvolvimento sustentável e da erradicação da pobreza e a estrutura institucional para o desenvolvimento sustentável. 


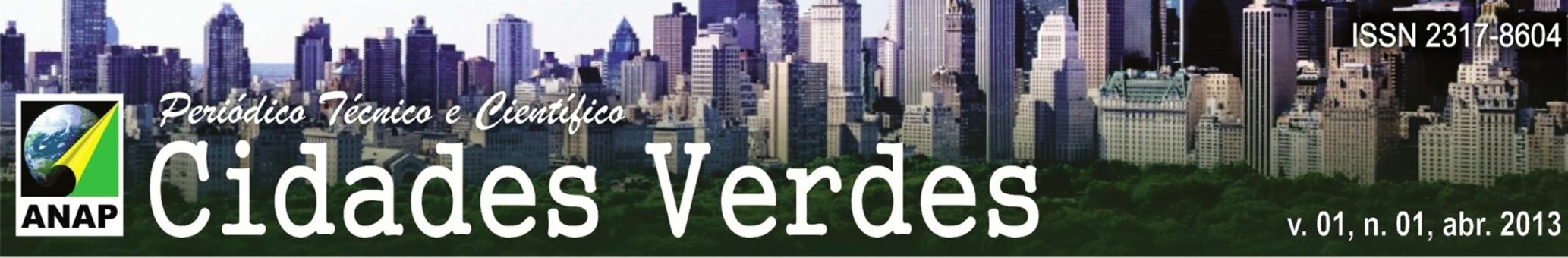

Nesta conjuntura é que análises sobre a qualidade ambiental do ambiente urbano surgem nas pesquisas científicas. Encontrar uma definição exata sobre o que é qualidade ambiental não é tarefa fácil, uma vez que a mesma relaciona-se à qualidade de vida e ambas requerem outras análises tanto qualitativas quanto quantitativas. Todavia, de forma objetiva pode-se pensar a qualidade ambiental como "uma interação e um equilíbrio entre o meio ambiente e as atividades que envolvam a vida do ser humano" (MACHADO, 1997, p. 17).

Nesta perspectiva, Mota (1999, p. 31) entende a qualidade ambiental como um "equilíbrio entre elementos da paisagem urbana através de um ordenamento do espaço, conciliando principalmente os benefícios da vegetação com os diversos tipos de uso do solo através de um planejamento", isto porque quando o ser humano apropria-se do ambiente natural, na intenção de construir cidades ou apenas expandi-las, o primeiro impacto se dá sobre a vegetação, pois ela é removida da superfície.

A retirada da vegetação devido ao processo de urbanização - intensificado a partir da década de 1970 em todo país, influenciado pelo intenso fluxo de migrações do ambiente rural para o ambiente urbano - conduziu a um crescimento desordenado das cidades, o que refletiu diretamente em alterações no ambiente, tais como, a ocorrência de temperaturas extremas tanto no verão quanto no inverno e de ilhas de calor, em função da intensa massa de edificações e concreto; o aumento de enchentes devido à falta de árvores; ocorrência de chuvas ácidas devido à emissão de gases poluentes industriais, etc. (BRITO, 2006).

Assim, uma análise que se pretenda ambiental-urbana, requer também uma compreensão da prática sócio espacial, ou melhor, do modo pelo qual a vida se desenrola na cidade, enquanto formas e momentos de apropriação, pois desta maneira acredita-se que pensar em qualidade ambiental e qualidade de vida não se simplificaria apenas a noção de preservação do meio ambiente (CARLOS, 1984; CHRISTOFOLETTI, 1999).

É fato que a cidade tem um papel transformador do meio, devido às inúmeras alterações que proporciona por sua existência, como por exemplo, quando há a necessidade de sua expansão e a vegetação natural é retirada da superfície terrestre. No caso brasileiro, a expansão do fenômeno urbano ganhou força influenciado por uma forte 
transformação estrutural que englobou as dimensões econômica, política e principalmente social, já que o ordenamento e a integração do país ocorreu através de uma política de desenvolvimento econômico-social, concomitantemente ao início do intenso processo de industrialização e consequente êxodo rural, o que gerou uma ocupação desordenada e irregular do espaço urbano (LOMBARDO, LEITE e MOURA, 2003).

A urbanização transformou profundamente as características do ambiente que constituído de dois sistemas: um natural (meio físico e biológico) e outro urbano (construído pelo homem) sofreu impactos irreparáveis, já que sendo um sistema composto por diferentes componentes: hídricos, climáticos, a vegetação, o solo etc. infere-se que há influência entre os elementos que compõem este sistema. Logo, alterações, por exemplo, sobre a vegetação, pode modificar o clima, a qualidade da água e assim, sucessivamente (DREW, 1986; MOTA, 1999).

\section{ÁREAS VERDES: UMA CONTEXTUALIZAÇÃO CONCEITUAL}

No ambiente urbano as áreas verdes desempenham papel singular para que haja qualidade ambiental e qualidade de vida da população, sendo consideradas um dos indicadores quando se deseja aferir tais qualidades. Para tanto, é necessário compreender quais os principais conceitos que têm sido elaborados e utilizados em estudos científicos, demonstrando a importância destes espaços para a cidade.

Inicialmente, pode-se citar o que foi proposto por Llardent (1982 apud NUCCI, 2008; BOVO, 2009) que se valeu da expressão áreas verdes para designar: 1º) sistemas de espaços livres: que se referem ao conjunto de espaços urbanos ao ar livre aonde as pessoas possam descansar, passear e/ou praticar esportes em momentos de lazer, entretenimento e de ócio; $2^{\circ}$ ) os espaços livres: referem-se aos diferentes tipos de áreas verdes que constituem o sistema de espaços livres; $3^{\circ}$ ) zonas verdes, espaços verdes, equipamentos verdes: qualquer espaço livre aonde a vegetação seja predominante, sendo os parques, jardins e praças. 


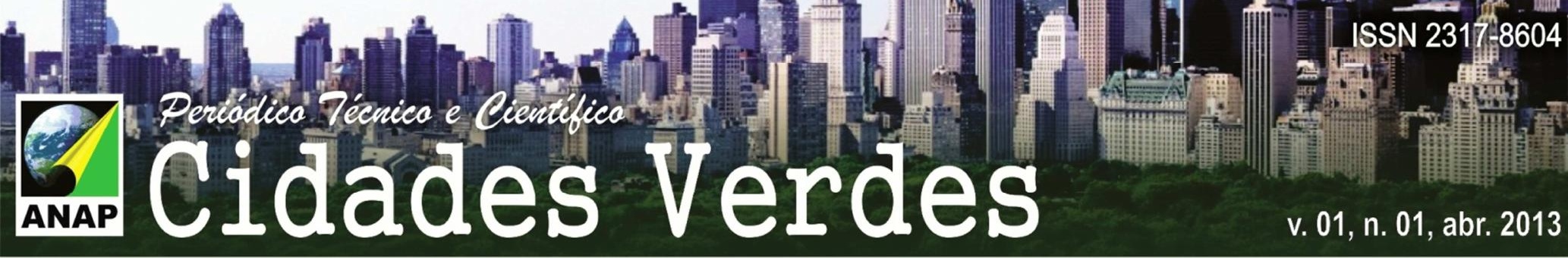

Para Cavalheiro (1982) as áreas verdes são correspondentes aos espaços livres de uso público que desempenham funções ecológicas, estéticas e sociais. É fundamental a presença de vegetação, de solo permeável e que a área seja livre de construções. $O$ autor ainda categoriza os espaços livres em três grupos: $1^{\circ}$ ) livres de uso particular: quintais e jardins particulares, etc.; $2^{\circ}$ ) livres de uso potencialmente coletivo: terrenos baldios urbanos não cercados, pátios de escolas, pátios de igreja, clubes e etc.; 3ำ) livres de uso público que são livremente acessíveis ao público em geral: ruas e avenidas (as calçadas), ruas de lazer, ruas de pedestres (calçadões), largos, praças, playground-playlot, parques, cemitérios, jardim botânico, bosques, reservas, parques naturais etc.

No trabalho de Lima, Cavalheiro, Nucci, Fialho e Del Picchia (1994) as áreas verdes correspondem aos espaços onde não há construção e sim o predomínio da vegetação, com $70 \%$ de permeabilidade do solo. Estão inclusas as praças, os jardins públicos e os parques urbanos; também é considerada a vegetação existente em canteiros centrais de avenidas, os trevos e rotatórias permeáveis das vias públicas e as áreas da cidade que exercem funções estéticas e ecológicas. Para os autores, os espaços livres seriam o conceito mais abrangente, no qual os demais estariam integrados. O parque urbano é uma área verde que desempenha funções ecológicas, estéticas e de lazer, compreendendo uma área maior que as praças e jardins. As praças seriam os espaços livres e públicos cuja função primordial é proporcionar às pessoas momentos de lazer. A arborização urbana também se encaixa como área verde e remete aos elementos vegetais de porte arbóreo dentro da cidade. Neste enfoque, as árvores plantadas nas calçadas fazem parte da arborização urbana, porém não integram o sistema de áreas verdes.

Os autores Zanin, Rosset e Dalavale (2007) classificam áreas verdes como os espaços livres de uso público, com cobertura vegetal predominantemente arbórea ou arbustiva que sejam capazes de proporcionar um microclima distinto no ambiente urbano em relação à luminosidade, temperatura e outros parâmetros associados ao bem-estar humano; com significado ecológico em termos de estabilidade geomorfológica e amenização da poluição e que suporta a fauna urbana, representada também por elementos esteticamente marcantes na paisagem, necessariamente com estruturas e 


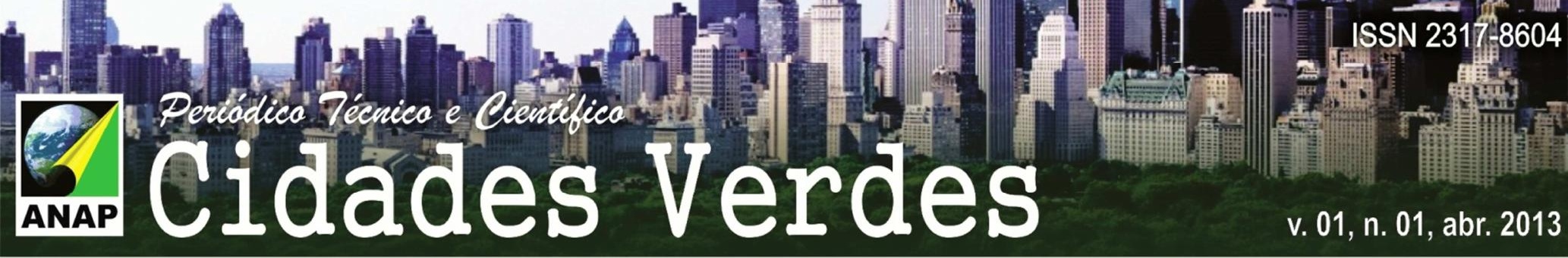

equipamentos para lazer instalados, ou seja, espaços que desempenham as funções ecológicas, sociais e estéticas e que poderão redundar entre si e/ou em benefícios financeiros (funções econômicas). Os autores categorizam as áreas verdes em: praças, parques e canteiros centrais.

Já Morero, Santos e Fidalgo (2007, p. 19) compreendem as áreas verdes como aqueles locais de domínio público "com atributos ambientais relevantes, capazes de propiciar atividades de lazer ao ar livre", áreas onde dominam a vegetação arbórea "praças, jardins e parques". Os autores ainda chamam a atenção para a distribuição espacial das áreas verdes alertando que "não devem privilegiar qualquer classe social, mas servir igualmente a toda população, suprindo suas necessidades e anseios para 0 lazer".

De maneira sucinta, Nucci (2008) considera áreas verdes os espaços livres onde predominam a vegetação e que cumprem fundamentalmente três funções: a estética, a ecológica e a de lazer; o solo permeável deve ocupar pelo menos $70 \%$ da área e que sejam públicas, sem regras rígidas de utilização.

É importante salientar que apesar da variedade de definições encontradas com o levantamento bibliográfico e documental, há pontos em comum entre as mesmas, tais como, para serem consideradas áreas verdes estes espaços devem apresentar pelo menos $70 \%$ de solo permeável, existência de vegetação arbórea e arbustiva e mobiliário básico para o lazer dos possíveis usuários.

Soma-se a isso, o fato de que outros aspectos importantes foram compreendidos em relação à presença da vegetação urbana. Por exemplo, nos estudos realizados por Amorim (1995) sobre a cidade de Presidente Prudente-SP, a autora constatou que a maioria das áreas verdes públicas encontravam-se em condições insatisfatórias de utilização; a situação era agravada ainda pela inexistência de vegetação e de mobiliário básico destinado ao lazer dos possíveis frequentadores. De acordo com a pesquisadora, o tratamento dado à vegetação era diferente no centro e na periferia: nos bairros mais centrais e nos que possuíam um padrão socioeconômico mais elevado, a qualidade da vegetação nas áreas verdes foi considerada satisfatória, já nos bairros periféricos, tal fato era raro. 
Para endossar a constatação de Amorim (2001) cita-se novamente Morero et. al. (2007, p. 19) que afirmam que apesar de o conhecimento científico comprovar os benefícios das áreas verdes para o ambiente urbano, ainda há uma tendência de se "economizar espaços para o lazer" contribuindo para a sua não efetivação, principalmente nos setores considerados mais pobres.

Outro fator importante diz respeito a carência de vegetação no ambiente urbano brasileiro, comprovado por pesquisa do Censo do Instituto Brasileiro de Geografia e Estatística (IBGE, 2010), onde investigou-se o entorno dos domicílios particulares urbanos brasileiros que se localizavam em quadras ou quarteirões, excluindo parte dos domicílios existentes nas favelas. Dentre os itens investigados estava a arborização do entorno, ou seja, a presença ou não de árvores no entorno do domicílio, não sendo considerados os jardins internos, por exemplo. Algumas informações da pesquisa referentes à arborização estão disponíveis na tabela abaixo:

Tabela 1: A Arborização Urbana de acordo com o IBGE (2010)

\begin{tabular}{|l|c|c|c|c|c|}
\hline \multicolumn{5}{|c|}{ Domicílios particulares permanentes (Próprio, alugado, cedido, outra) } \\
\hline Arborização & $\begin{array}{c}\text { Região } \\
\text { Norte }\end{array}$ & $\begin{array}{c}\text { Região } \\
\text { Nordeste }\end{array}$ & $\begin{array}{c}\text { Região } \\
\text { Centro- } \\
\text { Oeste }\end{array}$ & $\begin{array}{c}\text { Região } \\
\text { Sudeste }\end{array}$ & Região Sul \\
\hline Existente & 1075497 & 6452619 & 2634985 & 16422380 & 5287003 \\
\hline $\begin{array}{l}\text { Não } \\
\text { existente }\end{array}$ & 1853797 & 4038575 & 1155770 & 5907236 & 2042142 \\
\hline $\begin{array}{l}\text { Sem } \\
\text { declaração }\end{array}$ & 37658 & 90691 & 19395 & 226944 & 19516 \\
\hline Total & 2966952 & 10581885 & 3810150 & 22556560 & 7348661 \\
\hline
\end{tabular}

Fonte: IBGE, 2010. Organizado por: CUNHA SOUZA, 2013.

De acordo com os números da tabela e, considerando o total de domicílios por região, é possível inferir que a região Norte é a mais carente de arborização de entorno, apresentando aproximadamente $62,5 \%$ de carência. Em seguida, vem a região Nordeste 
com 38,2\%, depois Centro-Oeste com 30,3\%, região Sul com 27,3\% e região Sudeste, sendo esta a que apresenta menos carência, em torno de $26,2 \%$.

É importante esclarecer que o levantamento realizado constitui-se em uma abordagem quantitativa, pois considerou apenas a existência ou não de árvores no entorno dos domicílios. Dessa maneira, algumas situações podem ter sido escamoteadas, como o fato de que nas diferentes regiões algumas cidades concentram maiores índices de arborização, sendo até denominadas cidades verdes; pode acontecer também que apesar da carência de vegetação em determinada região, a mesma apresente em seu espaço urbano uma distribuição mais equitativa da arborização, característica de extrema importância, pois como visto, a existência de vegetação tem tanta importância quanto a sua distribuição homogênea pela cidade; dentre outras situações.

A ênfase aqui é dada sobre o fato de que a arborização urbana necessita de planejamento adequado para que esteja presente em toda a cidade e não concentrada em pontos específicos. Neste sentido, pode-se falar de um aspecto também importante ligado às áreas verdes, que é a questão do índice de arborização urbana classificado como saudável ao ambiente da cidade. A realidade é que este cálculo é feito em função dos objetivos de cada pesquisa, não existindo uma fórmula geral para realizá-lo e nenhuma porcentagem mínima de vegetação urbana que seja devidamente reconhecida.

Um dos índices mais utilizados e simples é o Índice de Áreas Verdes (IAV) que, de acordo com Toledo e Santos (2008, p. 84) é o índice que "denota a quantidade de espaços livres de uso público em $\mathrm{m}^{2}$ (metro quadrado) ou $\mathrm{km}^{2}$ (quilômetro quadrado) dividido pela quantidade de habitantes de uma cidade". De forma geral, para o cálculo do IAV a metodologia utilizada é a seguinte:

(1) $I A V=\sum \frac{A V}{H}$

Onde, na equação (1), temos que:

- IAV = Índice de Áreas Verdes.

- $\Sigma$ = Somatório

- AV = Número total das áreas das Áreas Verdes.

- H = Número total de habitantes no ambiente urbano (CAPORUSSO e MATIAS, 2008, p. 81). 


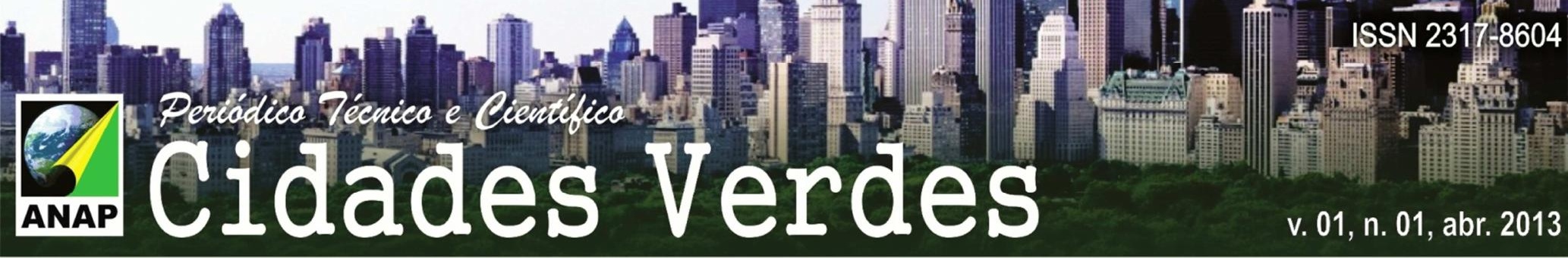

É fundamental salientar que este é um tipo simples de cálculo, caracterizado pelo somatório das áreas verdes dividido pelo número de habitantes da cidade; assim o resultado sempre se dá em função de fatores demográficos. Nesta perspectiva, o IAV pode ser elevado em certas localidades não pela quantidade de áreas verdes, mas pelo número reduzido da população local (CAPORUSSO e MATIAS, 2008). Logo, não é possível realizar generalizações ou comparações com índices de outras localidades, uma vez que cada cidade possui características próprias tanto demográficas quanto físicas.

Para Rosset (2005) os índices de áreas verdes expressam apenas uma informação quantitativa e não necessariamente o estado em que as áreas verdes se encontram ou como estão sendo utilizadas ou a distribuição das mesmas no ambiente urbano. Logo, é importante dar ênfase as particularidades de cada área urbana e, sabe-se que, independente da área urbana estudada, o fato é que a presença de vegetação configurase de fundamental importância e requer adequado planejamento urbano.

\section{A IMPORTÂNCIA DAS ÁREAS VERDES PARA AS CIDADES}

Os benefícios gerados em função da presença de vegetação no espaço urbano é evidente, destaca-se primeiramente os relacionados ao clima urbano: minimização das ilhas de calor, fenômeno que ocorre em função da ausência da vegetação e da impermeabilização do solo nas cidades; a contribuição da vegetação no processo de evapotranspiração que gera um maior conforto térmico e melhora a qualidade e umidade do ar.

Neste sentido, Sewel (1978) e Falcón (2007) mostram que a vegetação urbana realmente contribui para a redução da contaminação atmosférica, porque as árvores têm a capacidade de consumir grande parte do Dióxido de Carbono (CO2) e em contrapartida, produzir grandes quantidades de Oxigênio $(O)$, além de filtrar a poeira e elementos contaminantes, o que ocasiona em uma melhora na qualidade do ar. Outro fator se refere a suavização das temperaturas extremas, pois a intensa massa de concreto e edificações faz com que no verão haja um aumento significativo da temperatura e a atmosfera seja 
funções como as ornamentais, paisagísticas, o controle de ruídos e filtragem da poluição atmosférica, também como modificadora do microclima, adequando o comportamento térmico nas cidades. A existência de verde no ambiente urbano deve obedecer ao planejamento urbano, para que sejam estabelecidos parâmetros qualitativos e quantitativos que ressaltem os benefícios gerados por estas áreas da cidade.

Para Pivetta e Silva Filho (2002) as benfeitorias da vegetação no ambiente da cidade correspondem a vários aspectos: $1^{\circ}$ ) proporcionam bem estar psicológico ao homem; $2^{\circ}$ ) proporcionam melhor efeito estético; $3^{\circ}$ ) proporcionam sombra para os pedestres e veículos; 4ํำ protegem e direcionam o vento; 5ำ amortecem o som, amenizando a poluição sonora; 6º) reduzem o impacto da água de chuva e seu escorrimento superficial; $7^{\circ}$ ) auxiliam na diminuição da temperatura, pois absorvem os raios solares e refrescam o ambiente pela grande quantidade de água transpirada pelas folhas; $8^{\circ}$ ) melhoram a qualidade do ar; e $9^{\circ}$ ) preservam a fauna silvestre.

Em suma, é possível dar visibilidade às três principais funções desempenhadas pelas áreas verdes: ecológicas, estéticas e sociais, agindo ao mesmo tempo sobre o lado psicológico e físico do ser humano:

A vida em um quadro sem beleza tem uma influência nefasta no equilíbrio psíquico do homem; árvores verdes e gramados têm um efeito repousante para o espírito e desenvolvem no homem o gosto pelo belo. As emoções sentidas ante uma bela paisagem, de linhas bonitas, áreas verdes e água, estão entre as experiências mais fortes e mais enriquecedoras da personalidade (HAUSER, 1965, p. 195).

\section{CONSIDERAÇÕES FINAIS}

Os estudos científicos demonstram que, atualmente, o cenário das cidades brasileiras é de carência de áreas verdes públicas e/ou ausência de manutenção adequada das que já estão instituídas. Por outro lado, há certo incentivo para o reconhecimento e valorização destes espaços da cidade, já que os seus benefícios já são comprovados, englobando principalmente, os relacionados aos aspectos ecológicos, 
sociais e estéticos. Vale ressaltar que a vegetação é um dos indicadores considerados em análises sobre qualidade ambiental urbana e qualidade de vida.

A preocupação com a qualidade do ambiente urbano tem se destacado nos últimos anos, entretanto, quando se trata do indicador "áreas verdes", o descaso dos órgãos públicos apresenta-se com bastante evidência, pois há certa tendência de se economizar os espaços para a instituição destas áreas. Um sistema de áreas verdes bem planejado, estruturado que visa uma distribuição homogênea pela cidade, considerando os processos de manejo adequados, tem a capacidade de proporcionar à cidade e à sua população um ambiente agradável e saudável, principalmente, no que se refere ao clima, pois sabe-se que a presença de vegetação ameniza as temperaturas extremas, tanto no inverno quanto no verão, contribuindo para o conforto térmico e minimização do fenômeno ilha de calor; no que se refere à fauna, a vegetação abriga grupos variados de pequenos animais; no que se refere ao lazer da população, são áreas de fácil acesso, sendo locais de interação do cidadão com elementos naturais, dentre outras.

Deste modo, é indispensável que haja cobertura vegetal arbórea e arbustiva em todos os espaços da cidade consistindo em um sistema de áreas verdes, já que sua presença contribui positivamente no equilíbrio ecológico, refletindo na qualidade ambiental e de vida da população da cidade.

\section{REFERÊNCIAS}

AMORIM, M. C. C. T. Caracterização das Áreas Verdes em Presidente Prudente. In: SPÓSITO, Maria. E. B. Textos e Contextos para a Leitura Geográfica de uma Cidade Média. Presidente Prudente: Programa de Pós-Graduação em Geografia. FCT/UNESP GASPERR. 2001.

BARBOSA, R.V.R., BARBIRATO, G. \& VECCHIA, F.A.S. (2003) Vegetação urbana: análise experimental em cidade de clima quente e úmido. In: VII ENCONTRO NACIONAL DE CONFORTO NO AMBIENTE CONSTRUÍDO e III CONFERÊNCIA LATINO-AMERICANA SOBRE CONFORTO E DESEMPENHO ENERGÉTICO DE EDIFICAÇÕES, Curitiba. Anais. PUC - ANTAC (no prelo).

BOVO, M. C. Áreas verdes urbanas, imagem e uso: um estudo geográfico sobre a cidade de Maringá PR. (Tese de Doutorado). Presidente Prudente - SP, 2009.

BRITO, F. O deslocamento da população brasileira para as Metrópoles. Estudos Avançados. V. 57, p. 221236, USP, 2006.

CAMARGO, C. E. S. Qualidade Ambiental Urbana em Presidente Prudente. Dissertação (Mestrado em Geografia). UNESP, Presidente Prudente, 2007. 
CAPORUSSO, D. \& MATIAS, L.F. Áreas verdes urbanas: avaliação e proposta conceitual. I Simpósio de Pós-Graduação em geografia do Estado de São Paulo SIMPGEO-SP. Anais. Rio Claro, 2008.

Instituo Brasileiro de Geografia e Estatística. Censo Demográfico 2010: Características urbanísticas do entorno dos domicílios. Disponível em:<

http://www.ibge.gov.br/home/estatistica/populacao/censo2010/entorno/entorno_tab_norte_pdf.shtm>. Acesso em 24 de Jan. 2013.

CARLOS, A. F. A. O Meio Ambiente e o Discurso Ecológico. In: Revista do Departamento de Geografia da USP. n. 8. Faculdade de Filosofia, Letras e Ciências Humanas, 1994.

O Espaço Urbano: novos escritos sobre a cidade. São Paulo: Contexto, 2004.

CASCINO, F. Educação Ambiental: princípios, história, formação de professores. 4ª ed. - São Paulo: Editora SENAC São Paulo, 2007.

CAVALHEIRO, F. O planejamento dos espaços livres - o caso de São Paulo. Revista Silvicultura/Instituto Florestal, v.16 , parte 3, São Paulo, 1982.

CAVALHEIRO, F. et. al. Proposição de terminologia para o verde urbano. In: Boletim Informativo da Sociedade Brasileira de Arborização Urbana, Rio de Janeiro, ano VII, nํ3, 1999. Disponível : <http://www.geografia.ufpr.br/laboratorios/labs/index.php>. Acesso em: 01 Jun. 2012.

CHRISTOFOLETTI, A. Impactos no Meio Ambiente ocasionados pela Urbanização no Mundo Tropical. In: SOUZA, M. A.A.; SANTOS, M.; SCARLATO, F. C.; ARROYO, M. O novo mapa do mundo. Natureza e Sociedade de Hoje: Uma leitura geográfica. 2ª ed. São Paulo: Hucitec, 1994.

DREW, D. Processos interativos homem-meio ambiente. Tradução de João Alves dos Santos. - São Paulo: DIFEL, 1986.

FALCÓN, A. Espacios verdes para uma ciudad sostenible: planificación, proyecto, mantenimiento y gestión. Barcelona, España: Editorial Gustavo Gill, SL, 2007.

GREGORY, K. J. A Natureza da Geografia Física. Eduardo de Almeida Navarro (trad.). Rio de Janeiro: Editora Bertrand Brasil S.A., 1985.

GUZZO, P. Estudo dos espaços livres de uso publico da cidade de Ribeirão Preto/SP, com detalhamento da cobertura vegetal e áreas verdes de dois setores urbanos. Dissertação (Mestrado em Geociências e Meio Ambiente), UNESP - Universidade Estadual Paulista, Rio Claro, 1999, 125p.

HAUSER, P. M. Manual de pesquisa social nas zonas urbanas. São Paulo: Livraria Pioneira Editora/UNESCO, 1978.

LIMA, A.M.L.P.; CAVALHEIRO, F.; NUCCI, J.C.; SOUZA, M.A. del B.; FIALHO, N. de O. e DEL PICCHIA, P.C.D. Problemas de utilização na conceituação de termos como espaços livres, áreas verdes e correlates. In: Il Congresso Brasileiro de Arborização Urbana, São Luís, de 18 a 24 de Setembro de 1994, p. 539549.

LEAL, L. N. Pesquisa do IBGE mostra carência de verde em cidades (2012). Disponível em:< http://exame.abril.com.br/meio-ambiente-e-energia/noticias/pesquisa-do-ibge-mostra-carencia-de-verde-emcidades>. Acesso em 24. Jan. 2013.

LEITE, M. A. F. P. A Natureza e a Cidade: Rediscutindo suas Relações. In: SOUZA, M. A. A. et. al. O novo mapa do mundo. Natureza e Sociedade de Hoje: Uma leitura geográfica. $2^{\mathrm{a}}$ ed. São Paulo: Hucitec, 1994. 
LOMBARDO, Magda Adelaide. Vegetação e Clima. In: Encontro Nacional sobre Arborização Urbana. Curitiba. Anais FUPEF/PR, 1990.

MACHADO, L. M. C. P. Environmental quality: quantitative and perceptive indicators. In: Indicadores ambientais. Coordenação de Nilson Borlina Maia, Henry Lesjak. Sorocaba: s.n., 1997, p. 15-21.

MINAKI, C. Qualidade ambiental urbana em Guararapes/SP. Dissertação (Mestrado em Geografia). Presidente Prudente, 2009.

MORERO, A. M.; SANTOS, R. F.; FIDALGO, E. C. C. Planejamento ambiental de áreas verdes: estudo de caso de Campinas - SP. Revista do Instituto Florestal, v19, n1, p. $19-30$, jun. 2007.

MOTA, S. Urbanização e Meio Ambiente. Rio de Janeiro: ABES, 1999.

NUCCI, J. C. Qualidade ambiental e adensamento urbano: Um estudo de ecologia e Planejamento da Paisagem aplicado ao distrito de Santa Cecília (MSP). 2ª . ed. - Curitiba: O Autor, 2008. 150p. ; il.

PIVETTA, K. F. L. \& SILVA FILHO, D. F. Arborização Urbana. Boletim Acadêmico (Série Arborização Urbana). UNESP/FCAV/FUNEP. Jaboticabal-SP, 2002. Disponível em:

<www.uesb.br/flower/alunos/pdfs/arborizacao_urbana\%20Khatia.pdf>. Acesso em 29 de Jan. 2013.

Presidente Prudente. São Paulo. Disponível em:

<http://www.ibge.gov.br/cidadesat/painel/painel.php?codmun=354140\#>. Acesso em: 19 de Julho, 2012.

REZENDE, D. A. \& DIAS, N. C. Indicadores para gestão ambiental urbana: modelagem e mapeamento. In: XIII Seminário de Iniciação Científica da PUCPR, 2005, Curitiba. Caderno de Resumos PUCPR PIBIC 2005. Curitiba: Editora Champagnat - PUCPR, 2005, v. 01. P. 54-56. Disponível em:

<http://www.cefetcampos.br/observatórioambiental>. Acesso em: 01 jun. 2012.

RODRIGUES, A. M. Novas práticas e novas matrizes discursivas? In: SOUZA, Maria Adélia A. et. al. 0 novo mapa do mundo. Natureza e Sociedade de Hoje: Uma leitura geográfica. $2^{\mathrm{a}}$ ed. São Paulo: Hucitec, 1994.

ROSSET, F. Procedimentos Metodológicos pata estimativa do índice de áreas verdes públicas. Estudo de caso: Erechim, RS. Dissertação de Mestrado. Universidade Federal de São Carlos. São Carlos - SP, 2005.

SILVA JÚNIOR, Paulo Roberto. A importância das áreas verdes. Centro de Distribuição de Amostras. Piracicaba, São Paulo, 2006.

Sobre a RIO+20. Disponível em: <http://www.rio20.gov.br/sobre_a_rio_mais_20>. Acesso em: 17 julho, 2012.

TOLEDO, F. S.; SANTOS, D. G. Espaços Livres de Construção. Revista da Sociedade Brasileira de Arborização Urbana, Piracicaba - SP, v3, n1, p. 73-79, mar. 2008.

TROPPMAR, Helmut. "As áreas verdes em sistemas urbanos". In: Biogeografia e Meio Ambiente. Rio Claro: Geografia Teorética, 1995.

UGEDA JÚNIOR, J. C. Clima urbano e planejamento na cidade de Jales-SP. Tese de Doutorado. Universidade Estadual Paulista “Júlio de Mesquita Filho". Presidente Prudente, 2011. 
